\title{
Strengthening and Repair of a Precast Reinforced Concrete Residential Building
}

\author{
M. Jamal Shannag ${ }^{a^{*}}$, Mahmoud Higazey a \\ ${ }^{a}$ Civil Engineering Department, King Saud University, Riyadh, Saudi Arabia. \\ Received 04 September 2020; Accepted 18 November 2020
}

\begin{abstract}
The deterioration or ageing of the existing infrastructures coupled with increased safety requirements necessitate immediate strengthening. Developing long lasting and cost effective repair techniques and materials continue to capture the attention of concrete professionals worldwide. The main purpose of this investigation was to extend the life span of a multi-storey precast reinforced concrete structure built in Riyadh 40 years ago. The condition assessments relied on analytical tools, visual, field and laboratory experiments for core samples collected from the building. The analytical checks of the building revealed considerable deflections of some slabs because of design error. The field and chemical analysis tests performed, confirmed the occurrence of durability defects as a result of poor workmanship during the construction stage. Several state-of-the-art repair techniques and materials were used for enhancing the service life of the structure at a minimum cost. The Repair strategy implemented included, removal of the deteriorated concrete, pouring a bonding agent on the surface of the damage, followed by injecting high strength cementitious grouts, supporting the deflected slabs using I-section steel beams, using cathodic protection to prevent corrosion, strengthening the columns and beams using carbon fiber reinforced polymer (CFRP) sheets, and steel jackets.
\end{abstract}

Keywords: Steel Corrosion; Precast Concrete; Cement Grout; Repair; Cracks; Buildings.

\section{Introduction}

Usually concrete structures show different types of defects during their lifetime starting from fine plastic shrinkage cracks to deflection problems that may lead to collapse in some cases. Despite the precautions and safety factors taken during the design stage, execution process, and usage of the facility, defects continue to appear in many parts of the structure. Once the diagnosis and the root causes of those defects are defined clearly, they are more likely to be prevented by choosing the most appropriate repair techniques available. ACI committee 546 [1] proposed the following steps for maximizing the service life of deteriorated concrete structures: condition evaluation, determination of the causes of deterioration, selecting repair methods and materials, preparation of drawings and specifications, execution of the work. The emphasis of material selection for structural repair has shifted towards inhibiting renewed corrosion of steel in the repair patch and preventing initial corrosion, [2]. The corrosion of reinforced concrete (RC) has always been an issue of great concern for concrete practitioners and researchers worldwide. Reinforced concrete structures are corroded due to several environmental factors, such as chloride, carbonation and temperature. Reinforcement corrosion is one of the most serious durability problems that requires urgent solutions throughout the world. In United States, approximately $15 \%$ of the nation's bridges are structurally deficient due to steel corrosion. In North Africa, and in the Middle East, some buildings have been destroyed because of steel reinforcement corrosion,

* Corresponding author: mjshanag@ksu.edu.sa

http://dx.doi.org/10.28991/cej-2020-03091630

(c) 2020 by the authors. Licensee C.E.J, Tehran, Iran. This article is an open access article distributed under the terms and conditions of the Creative Commons Attribution (CC-BY) license (http://creativecommons.org/licenses/by/4.0/). 
[3, 4]. In Saudi Arabia where concrete is the most commonly used construction material, and hot and dry (arid) weather conditions prevail, the government enforced strict durability measures to alleviate the damage levels for all types of defects [5].

Rehabilitation of concrete facilities forms a major part of the cost of construction activities in many countries worldwide, where the estimate for structural rehabilitation exceeds several billions of dollars a year. One of the major challenges facing the construction industry today is selection of a repair material that can enhance the strength and serviceability of the structure by considering the shape and amount of damage, construction cost, time and practicality. Recently, there has been a growing interest in using fiber reinforced polymer composites (FRPs) for repairing RC structures. Composite materials have gained wide acceptance by professional civil engineers due to increased knowledge and confidence in their applications [6,7]. State of the art reviews on strengthening reinforced concrete structures indicated that FRPs offer the engineer an outstanding combination of properties including high tensile strength and stiffness, high strength/weight ratio, high toughness, excellent durability, ease of installation, and reduced maintenance $[8,9]$.

Rastegarian and Sharifi [10] carried out a study on the correlation of inter-story drift and performance objectives in normal RC frames. They proposed equations capable of predicting inter-story drift at performance levels with a bit of story information precisely. Their equations can be used in the post-earthquake assessment of code designed intermediate RC moment frame to determine safety and damage levels. Balamuralikrishnan, and Saravanan [11] performed experimental and analytical study based on finite element analysis software ANSYS to assess the static load behavior of RC T-beams reinforced internally with GFRP reinforcements using solid 65 and link 8 element. Their experimental and analytical test results presented in terms of load-deflection graphs were almost identical. Venkatesh and Alapati [12] carried out a condition assessment of an existing concrete building using non-destructive tests. They have suggested several repair and strengthening techniques including column jacketing, shotcreting, and anticorrosive coatings for enhancing the life of the structure. Vijayalakshmi, et al., [13] proposed several methods for repairing a G+3 residential apartments located very close to sea shore, Besant Nagar, Tamil Nadu, India. Their repair strategy involved mainly removal of deteriorated concrete, and using polymer modified mortar for repair of RCC and injection of epoxy grout into masonry cracks, setting up a self-sacrificial anode to prevent corrosion of reinforcement, and glass fibre wrapping for columns to increase ductility.

Raza, et al., [14] provided state of the art review of several strengthening and repair techniques for RC columns, suggested by many researchers in the last two decades. The most commonly used repair techniques presented included: Reinforced concrete/mortar jacketing, steel jacketing, externally bonded fiber-reinforced polymer of carbon and glass types (CFRP/GFRP) jacketing, basalt fiber-reinforced polymer (BFRP), near-surface mounted (NSM), FRP sheets with steel jacketing, and high-performance materials with steel/FRP rebars or FRP wrapping. Parks, et al., [15] developed cost-effective technique for rapid seismic repair of severely damaged precast bridge assemblies, using a Carbon Fiber-Reinforced Polymer (CFRP) shell and epoxy-anchored headed bars to relocate the column plastic hinge. The repair method was capable of restoring the load and displacement capacity by relocating the plastic hinge to the original column. Fofiu, et al., [16], presented retrofitting procedure using carbon fiber strips for a precast reinforced concrete wall panel in order to restore its initial load bearing capacity.

The literature reviewed above indicated that there is a scarcity of information on repair and strengthening of precast reinforced concrete structures. Moreover, the past 40 years have witnessed a rapid growth of precast reinforced concrete buildings in Saudi Arabia due to their high performance, long life span, reduced maintenance requirements, and shorter construction time compared to conventional reinforced concrete structures. Since most of these buildings are over 30 years old, there is an urgent need for extending their service life due to economic considerations. The main objective of this investigation is to assess the damage level of 40 years old precast concrete building located in Riyadh, and propose state of the art and cost effective repair techniques for maximizing its service life. The subsequent sections will discuss the primary phases of this study including research methodology, condition evaluation, causes of concrete defects, and rehabilitation techniques suggested.

\section{Research Methodology}

The present study is concerned with the rehabilitation of multi-storey precast concrete building located in the eastern part of Riyadh (capital of Saudi Arabia). The structure represents a typical residential building that consist of four apartment units, and parking garages, each unit has six floors, with a total area of $1000 \mathrm{~m}^{2}$. The structure was built in 1980 as solid slabs supported on beams and columns with a total overall cost of 15 million Saudi Riyal, SR, (4.0 million US Dollars, \$). The front view of the building is shown in Figure 1; the architectural plans of the precast structure, and the enlarged architectural plan of a typical apartment unit are shown in Figures 2 and 3 respectively. The rehabilitation scheme of the buildings included visual inspection, classifying the types and locations of the defects, and the field tests required for determining their root causes, followed by proposing the most appropriate repair techniques. The detailed rehabilitation plan of this study is demonstrated using the flow chart shown in Figure 4. 


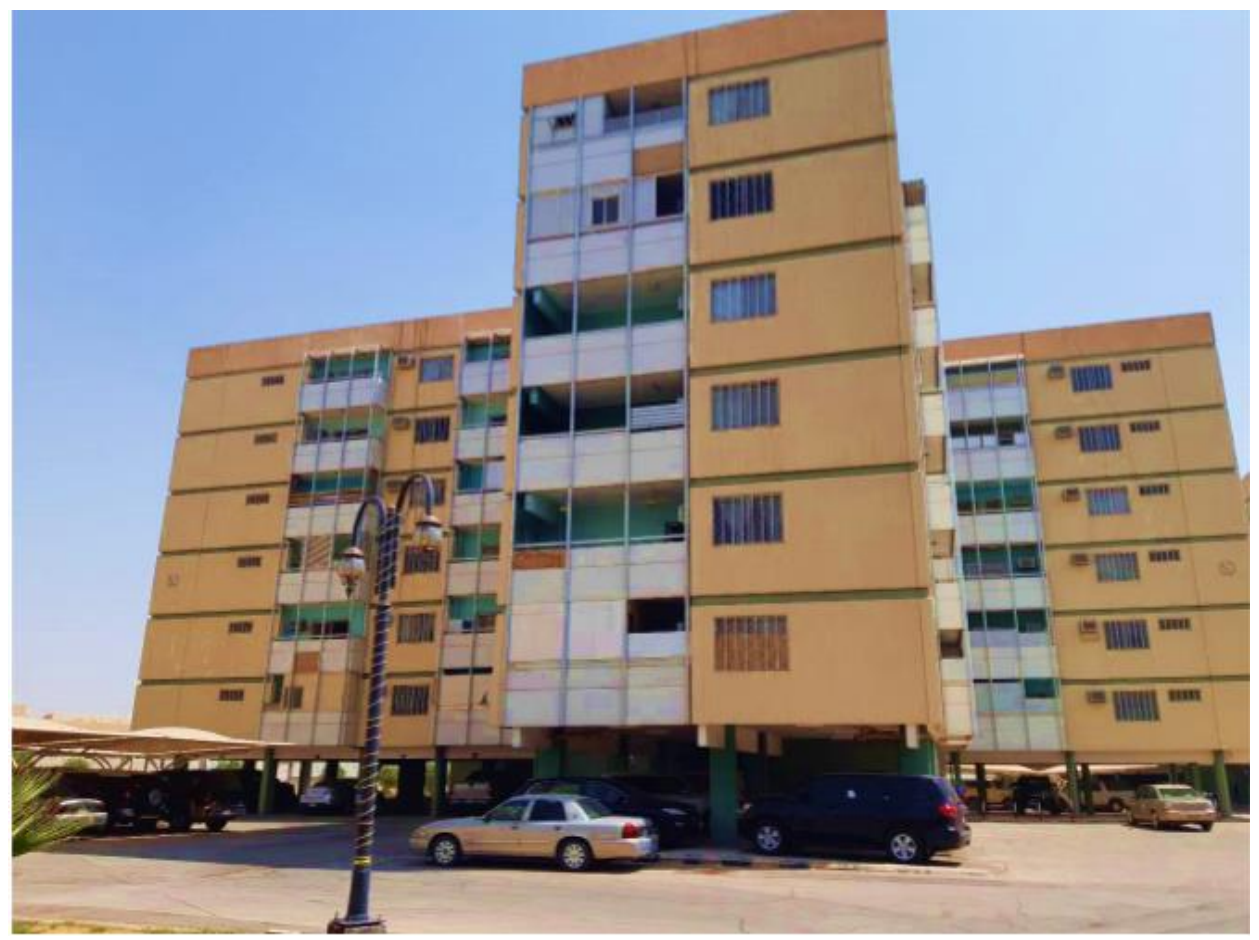

Figure 1. Front view of the precast building unit investigated

\section{Condition Evaluation}

The condition of the structure investigated was evaluated through checking the drawings and design calculations submitted by the engineering office to the contractor, visual inspection of all components of the building, and field tests for identifying the causes of damage.

\subsection{Design Check of the Building}

The design of the building was reviewed following SBC 304-18 and ACI 318-14 codes, [5, 17], using the same materials' strength and loading criteria given in the original design. The safety of the slabs was checked using CSISAFE design software and the same criteria mentioned above, by creating a separate model for each slab section as shown in Figure 5. The long-term deflection of some slabs was more than two times the deflection limit specified in the code for the same slabs. Furthermore, the safety of all elements of the buildings above the ground level, including beams, columns, walls and the whole floor slab, was also double checked by creating a 3D model in the ETABS structural analysis software as shown in Figure 6, using the cross-sectional dimensions, same material properties, and loadings used in the original design. The software analysis indicated that all beams, walls, and columns were safe. The deflection results of the full slab of the building, using the ETAB software program showed that $75 \%$ of the slabs were found to be unsafe as shown in Figure 7. This is in agreement with the deflection results reported using SAFE software for separate slabs.

\subsection{Visual Inspection}

An extensive visual inspection was carried out for all the structural members of the building to locate the defects and assess their damage levels. Two types of concrete defects were identified in this study: structural defects and durability defects. The structural defects observed included excessive deflections of many slabs, and moderate shrinkage induced cracks in some slabs, beams and columns. The durability defects included moderate to severe cracking due to water leakage and leaching in the slabs and beams of the bathrooms and balconies; leaching, spalling and scaling in some slabs; reinforcement corrosion, and alkali aggregate reaction in many places. The typical types of defects observed in the entire building along with their properties and photos are presented in Table 1. 


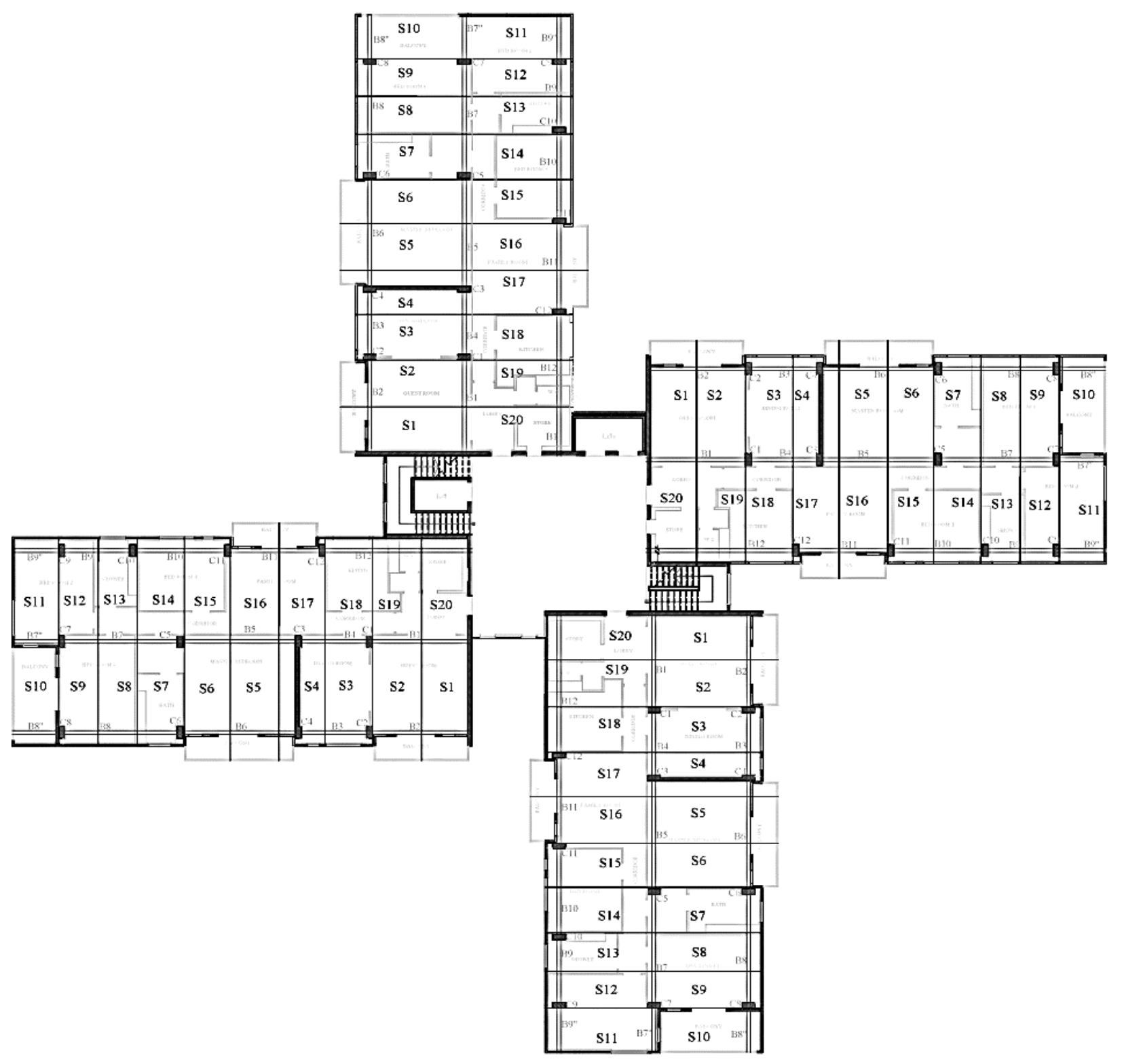

Figure 2. Architectural Plans of the precast building investigated

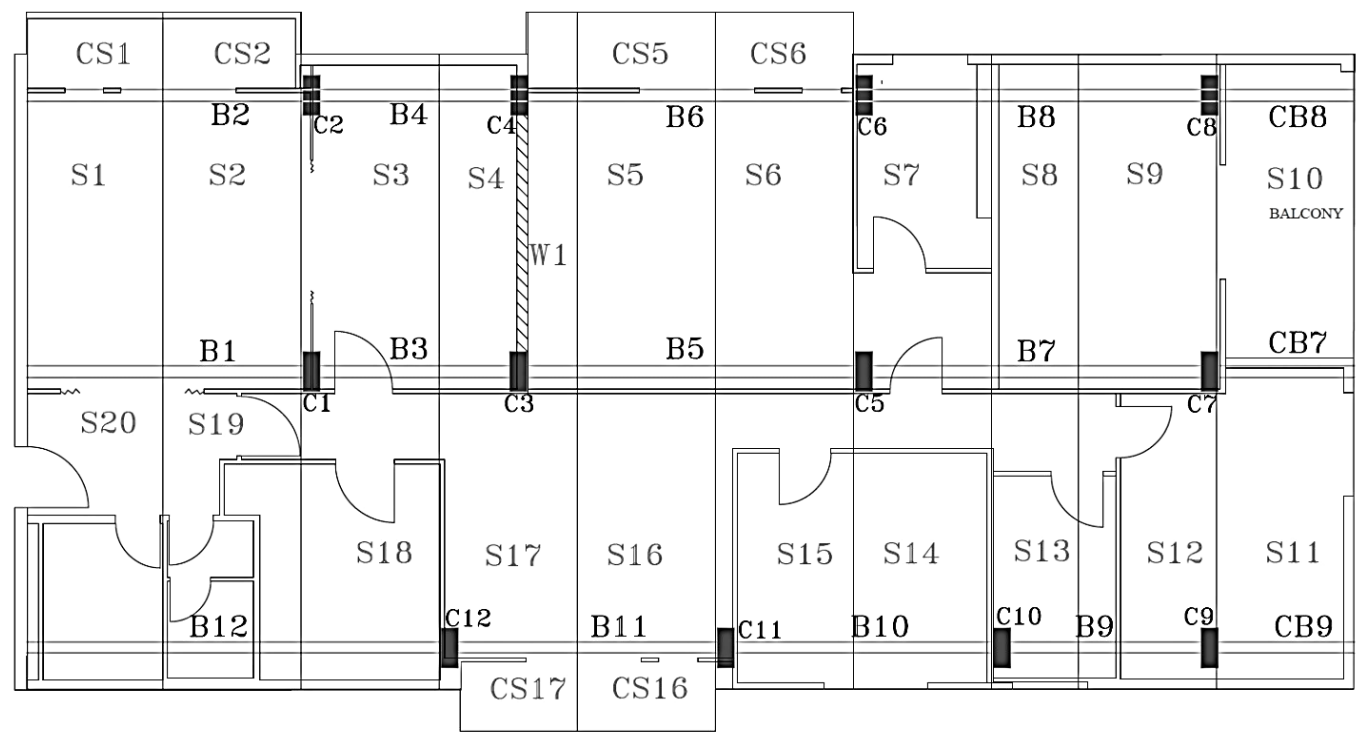

Figure 3. Enlarged Plan view of a single apartment 


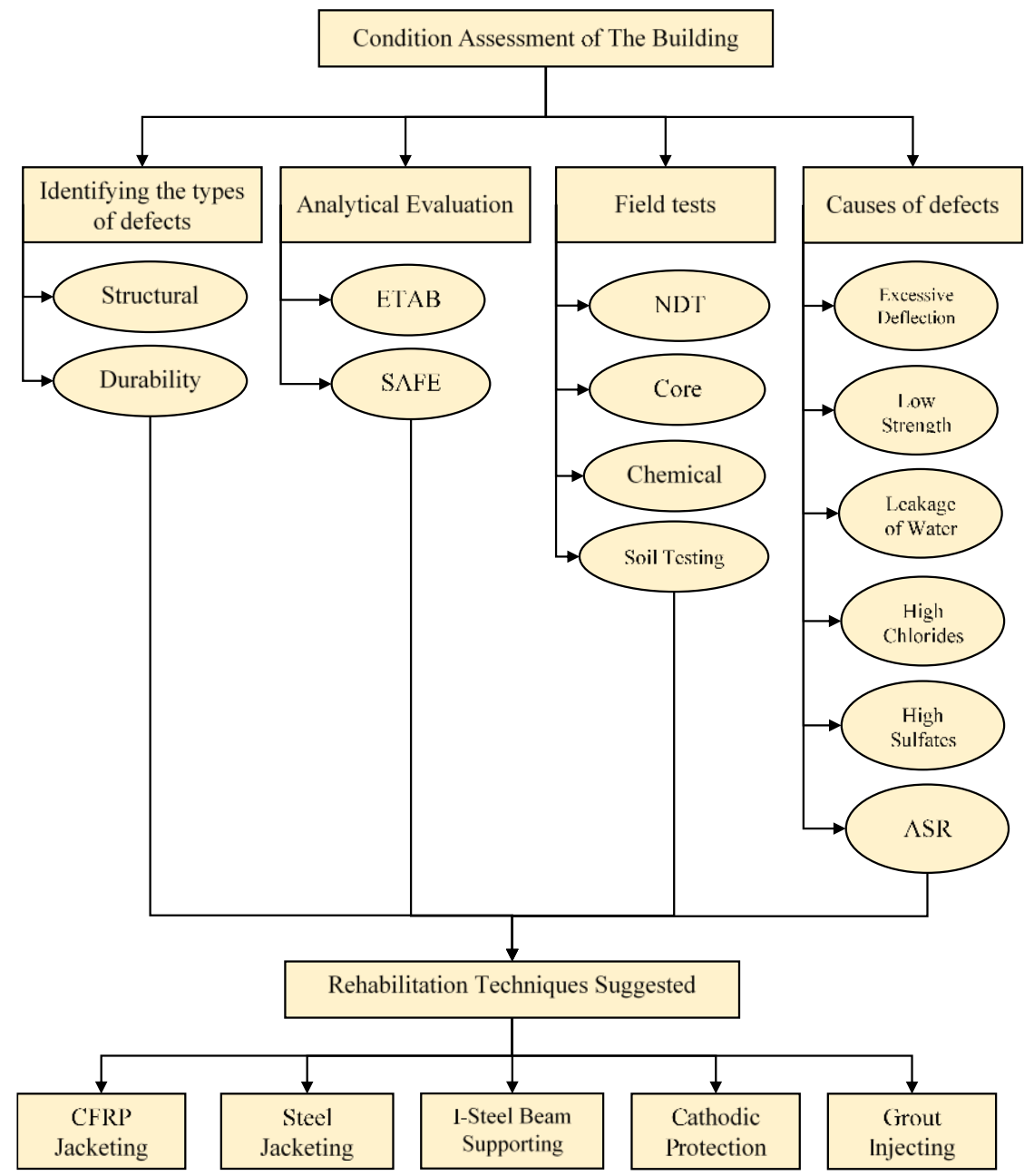

Figure 4. A flow chart demonstrating the rehabilitation plan of the precast building

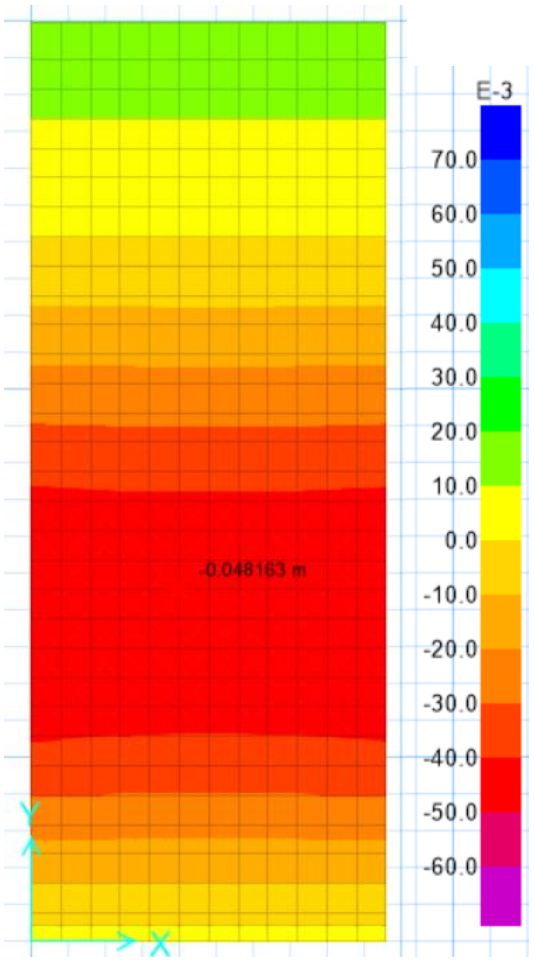

Figure 5. Deflection results of the original design of a single slab using SAFE Software 


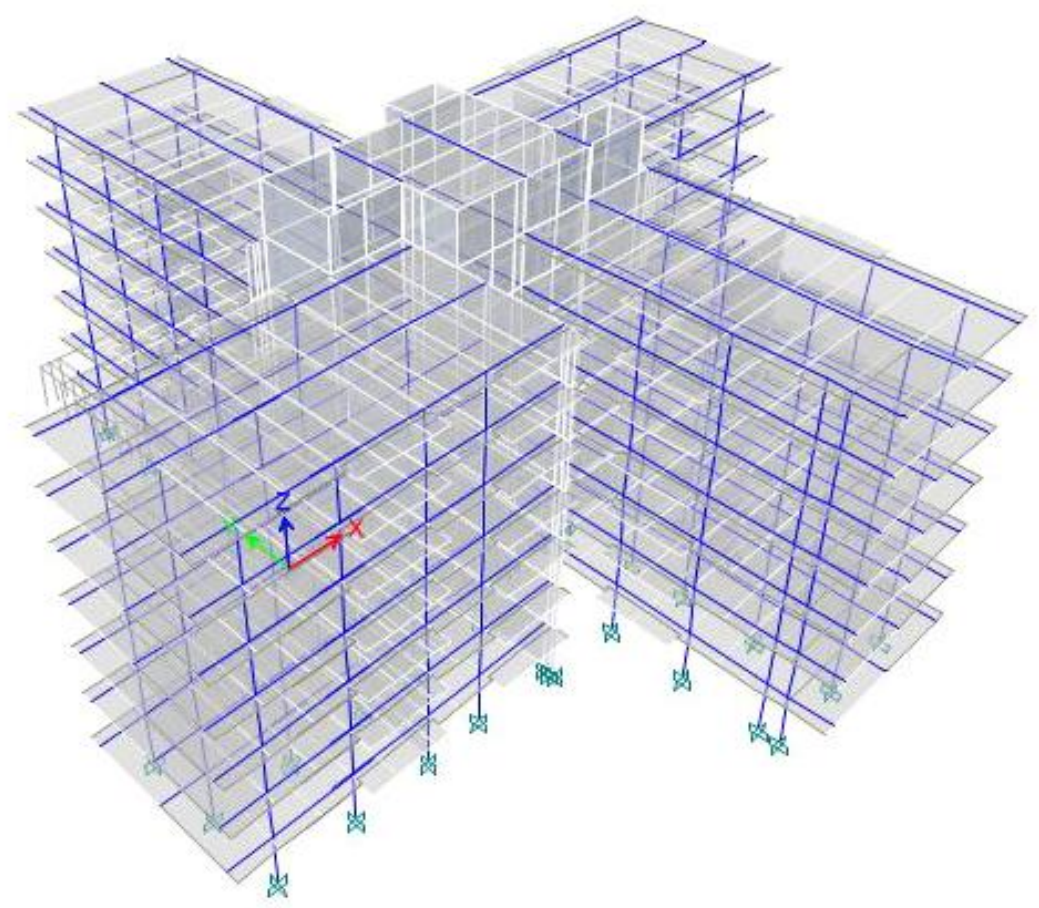

Figure 6. 3D model for the existing design of the building using EATBS

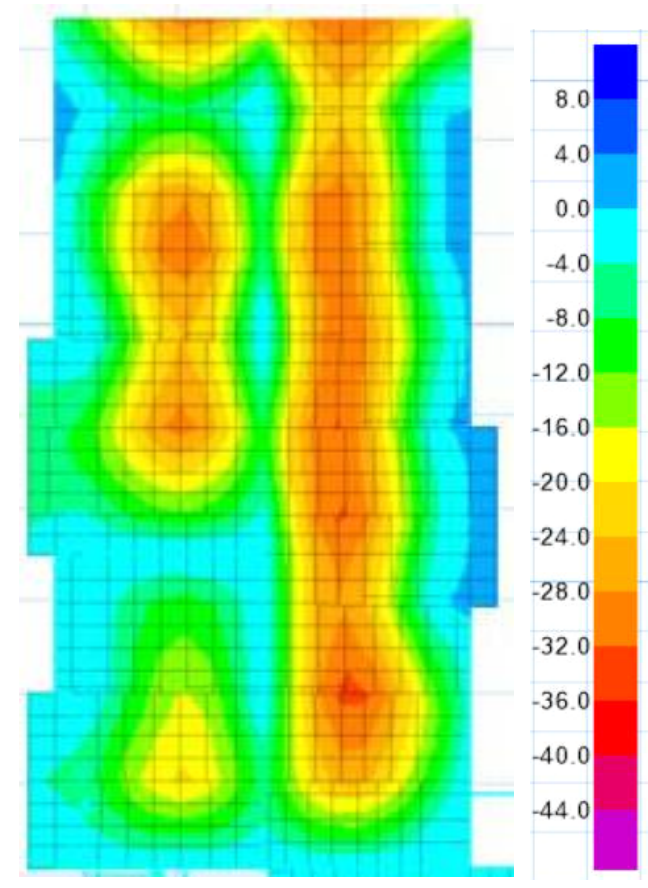

Figure 7. Deflection results of the original design of the full slab using ETABS Software

\subsection{Field Tests}

The field tests conducted to determine the root causes of the defects observed in the building are presented in the following sections.

\subsubsection{Deflections and Cracking}

The deflection was measured for slabs and beams in a typical apartment, using laser level device. The total number of slabs whose deflections were measured, was 645, out of which 114 slabs only satisfied the deflection limit specified in ACI code [17] as shown in Table 2. No excessive deflections were recorded for all the beams of the building unit. The widths, lengths and areas of the cracks observed on the surfaces of some members were measured using a micrometer and listed in Table 1. 


\subsubsection{Non-destructive Tests}

Schmidt rebound hammer test (ASTM C805), [18], was performed to estimate the in-place compressive strength for all the structural elements of the building. The values recorded ranged from 18 to 49 for columns, 18 to 44 for beams, and 15 to 45 for slabs as shown in Table 3. The corresponding estimated compressive strengths to these rebound numbers are listed in the Table 3.

Table 1. Types of concrete defects

\begin{tabular}{lccc}
\hline Member & Type of Defect & Severity of Crack & Illustrative Figures \\
\hline Columns & corrosion & Severe and spalling of \\
& concrete & & \\
& &
\end{tabular}

a) $\mathrm{P} 01-\mathrm{C} 10$

severe and spalling of

Beams

corrosion

water leakage, leaching and salt scaling

Beams

Slabs Alkali-Silica Reaction

Slabs

1.5 m length

Fine and moderate cracks concrete wide cracks, of

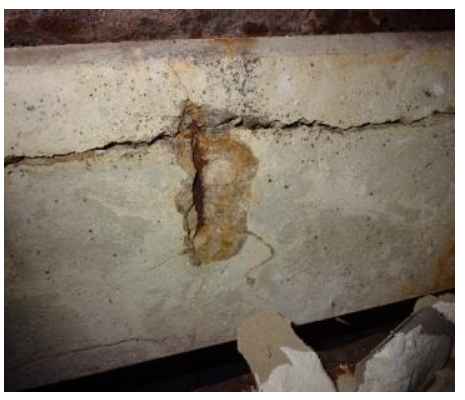

b) F05-B12

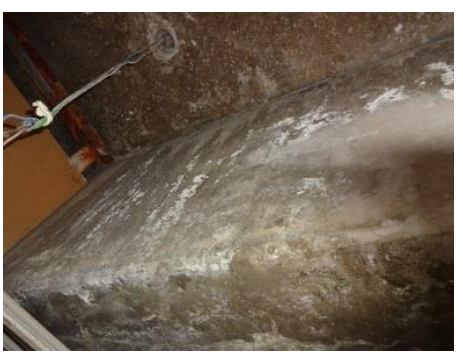

c) F06-B12

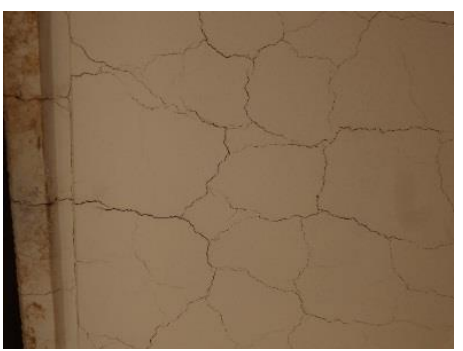

d) F06-CS2

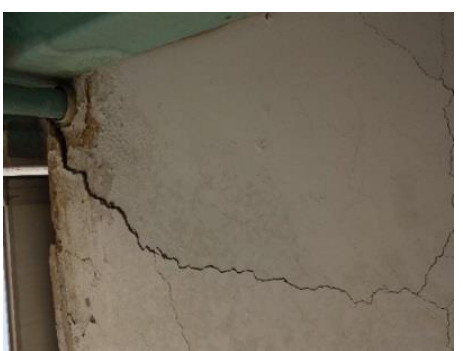

e) F04-CS16 
Slabs

Severe spalling of concrete and corrosion

Fine to moderate cracks, salt scaling and leaching

Slabs

Columns

moderate to fine cracks

corrosion and dry shrinkage

Columns

fine to moderate cracks

drying shrinkage

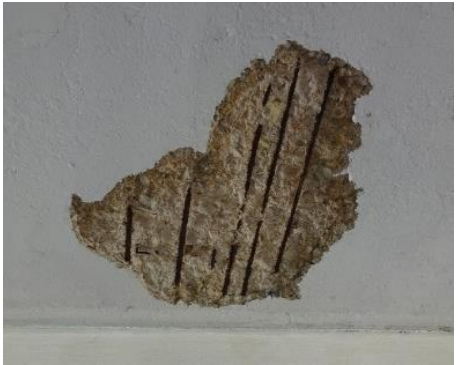

f) $\mathrm{P} 02-\mathrm{S} 12$

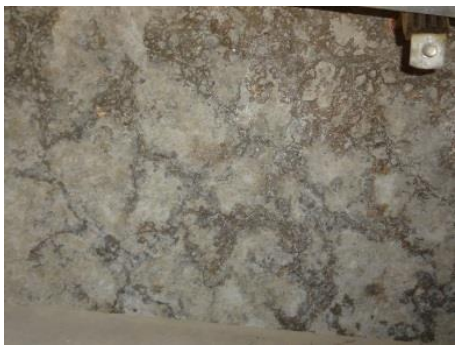

g) F14-S12

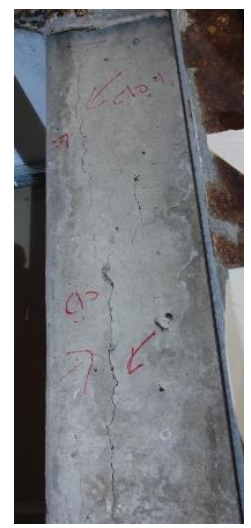

h) F15-C10

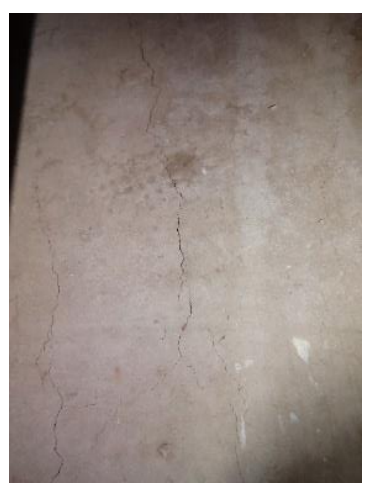

i) $\mathrm{F} 08-\mathrm{C} 09$

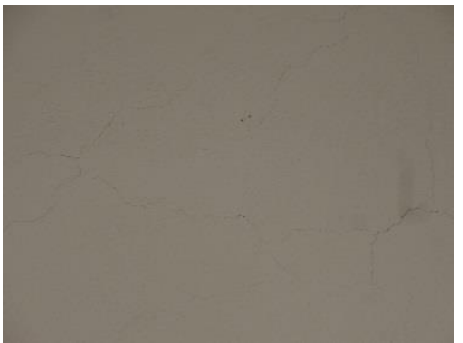


Table 2. Deflection results of the slabs

\begin{tabular}{cccccc}
\hline Element & Span $(\mathbf{m})$ & Deflection Limit $(\mathbf{m m})$ & Total Numbers & Exceeds Deflection & Highest Value (mm) \\
\hline Slabs & 4.80 & 20 & 645 & 531 & 49 \\
Cantilever slabs & 1.24 & 5 & 168 & 124 & 22 \\
\hline
\end{tabular}

Table 3. Results of core samples

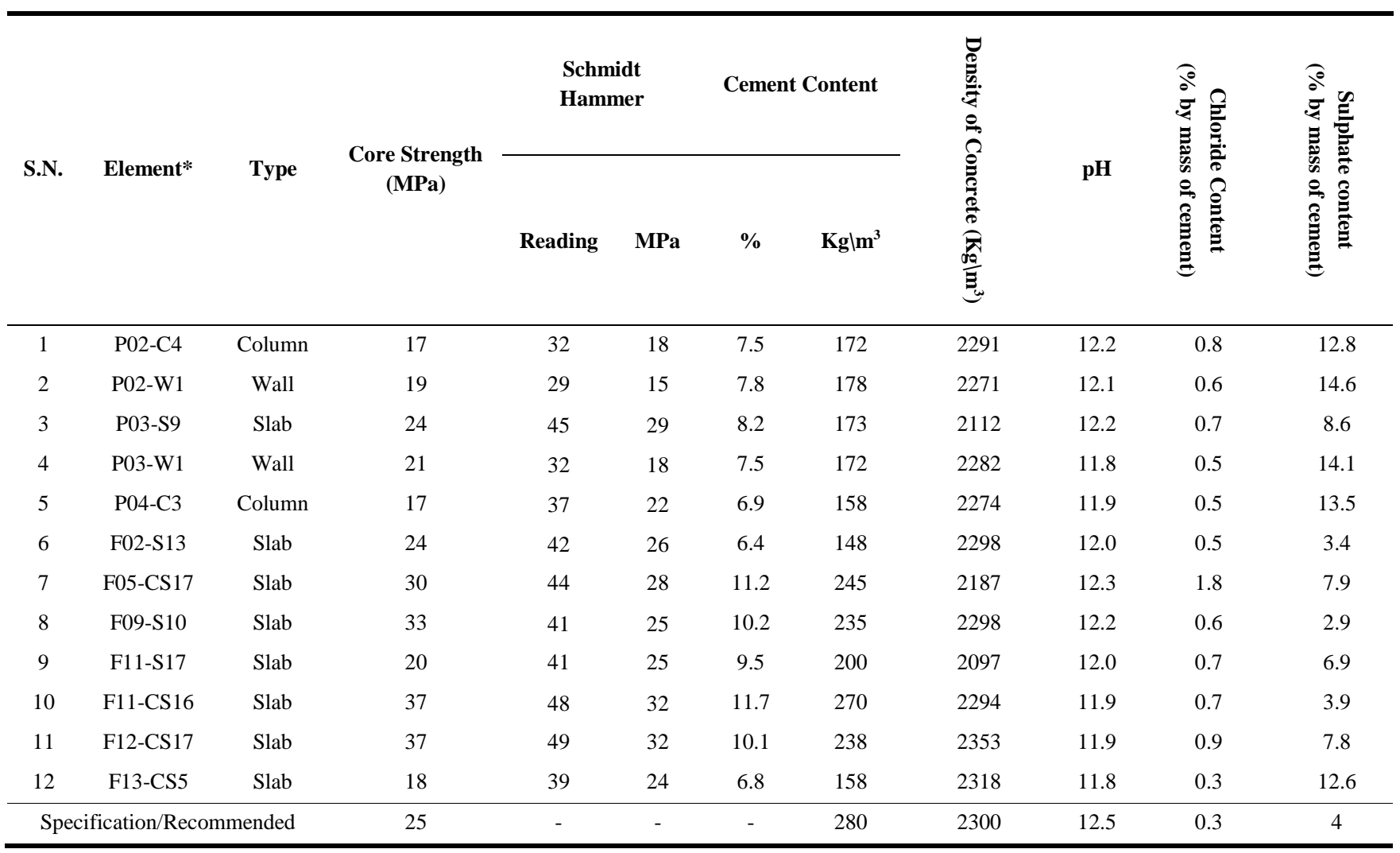

*F: Flat, B: Beam, S: Slab, W: Wall, C: Column, CS: cantilever slab

\subsubsection{Concrete Core Tests}

Based on the concrete strength estimated using non-destructive tests, 12 cores of $70 \mathrm{~mm}$ diameter were drilled at specific locations following ASTM C42 [19]. The actual compressive strength of the cores was determined following ASTM C39 [20], the results are presented in Table 3.

\subsubsection{Chemical Analysis}

Chemical analysis tests were performed on some core samples of concrete to determine the degree of alkalinity $(\mathrm{PH})$, the concentration of sulfates and chlorides in the concrete mix, and the cement content. The results of the chemical analysis for the structural elements inspected are presented in Table 3. The PH readings ranged from 11.8 to 12.3 , the concentrations of sulfates and chlorides ranged from 2.9 to $14.6 \%$ and 0.3 to $1.8 \%$, by mass of cement, respectively. The cement content ranged from 148 to $270 \mathrm{~kg} / \mathrm{m}^{3}$.

\subsubsection{Soil Testing}

Soil site investigation was carried out to determine the type of soil and its bearing capacity, and ground water level. The test results indicated that the soil was a poorly graded sandy soil with an allowable bearing capacity of $250 \mathrm{kN} / \mathrm{m}^{2}$. The ground water was not encountered in all boreholes drilled in this investigation, and the foundations were in good condition and did not require any repairs.

\section{Causes of Concrete Defects}

Prior to performing any type of repair work, the root causes of the defects observed in the building, must be identified as clearly as possible by a professional structural engineer. The visual inspection of the building indicated that there has been no major maintenance since a long time. Moreover, the review of the structural designs and field tests performed revealed that the main causes of the defects observed in the structure, can be summarized as follows: 


\subsection{Excessive Deflection}

The field tests presented in Table 2 indicated that the measured deflections for $82 \%$ of the slabs in the building exceeded the deflection limit specified in SBC304-18/ACI 318-14 [5, 17] for the existing slabs. This is in conformity with the analytical test results obtained using SAFE and ETABS softwares. The main reason for the excessive deflection was an error in estimating the thickness of the designed slabs. A thickness of $160 \mathrm{~mm}$ for the existing slabs was not sufficient to control the increase in long term deflections due to sustained loads, during the service life of the structure.

\subsection{Low Concrete Strength}

The large discrepancies among the Schmidt rebound numbers presented in Table 3 urged the need for taking core samples in order to determine the actual strength of the hardened concrete. The strength test results of some cores were less than the $85 \%(21 \mathrm{MPa})$ of the specified compressive strength, $25 \mathrm{MPa}$ of the concrete designed. This has confirmed the low strength predictions made by the Schmidt hammer and proved that a low quality concrete was used in some members, and poor workmanship was followed during the construction stage. Moreover, the chemical analysis test results revealed that the cement contents of most of the concrete mixes used, were less than those specified in the design calculations, $280 \mathrm{~kg} / \mathrm{m}^{3}$. This indicates that the concrete used, failed to meet the mix design procedures specified by the codes of practice and resulted in drying shrinkage cracks in some locations as shown in Table 1 ( $\mathrm{h}, \mathrm{i}$ and $\mathrm{j}$ ). The rebound numbers (18-49) and the strength results (17-37) MPa, reported in this investigation, compare fairly well with the experimental test results reported in the literature, (26 to 46 ) rebound numbers, with corresponding strengths (14-34) MPa [12] for a $20 \mathrm{MPa}$ reinforced concrete building.

\subsection{Leakage of Water}

The visual inspection indicated that the water is leaking from the pipes embedded in the beams of the bathrooms, and slabs of the balconies as shown in Table 1(c). The penetration of water through the pores of concrete increased further due to the low quality and high permeability of concrete cast in these structural members. This has aggravated the deterioration of concrete further by accelerating the occurrence of reinforcement corrosion, and alkai-aggregate reaction in many locations in the structure as shown in Table 1 (a, b, d, e, f and g).

\subsection{High Concentration of Chlorides}

The chemical analysis tests of the core samples taken from different locations in the structure showed that the chloride content of the concrete tested exceeded the limit specified in SBC304-18 code [5], by 2-3 times in some locations. The source of this chloride could be the aggregates and set accelerator (calcium chloride) used for making the concrete mixtures. In presence of moisture and oxygen, the penetration of chloride ions into concrete proceed by ionic diffusion mechanism associated with absorption of some chloride ions by the solid phase of the cement matrix [21]. This may lead to the formation of a large volume of expansive corrosion products on the surface of the reinforcing steel, which will exert more pressure on the surrounding concrete, and thus induce severe cracking and spalling as shown in Table 1 (a,b,e,f). Moreover, most of the PH values of the core samples presented in Table 3, were within the acceptable range of alkaline concrete (12-12.5), [21], indicating that carbonation may not be considered as a significant cause of reinforcement corrosion in this study. This is in conformity with the hot and dry conditions existing in Riyadh city, where the average annual relative humidity does not exceed $30 \%$.

The maximum chloride concentrations reported in this investigation for some members, $(1.8 \%)$ by mass of cement, corresponding to $4.86 \mathrm{~kg} / \mathrm{m}^{3}$, exceeded the maximum chloride content reported in the literature on a reinforced concrete building, $\left(1.07 \mathrm{~kg} / \mathrm{m}^{3}\right)$, by four times [12]. This indicates that chloride corrosion was the most serious problem causing the severe damage observed in some members of the precast structure. Moreover, the PH values reported in the present investigation (11.8-12.3) were larger than those reported in the literature for the same building (9.6-11.52), [12]. This shows that carbonation was mainly responsible for initiating the corrosion observed in the reinforced concrete building.

\subsection{High Concentration of Sulfates}

The chemical analysis tests of the core samples taken from some locations in the structure have also shown that the sulfate content of the concrete tested exceeded the limits specified in SBC304-18 and BS1881, [5, 21] codes by 3 and 7 times respectively. Such a severe concentration of sulfates, magnesium sulfate in particular had an aggressive decomposing action on concrete in a humid environment, [21], and caused an increase in permeability of concrete, leaching and salt scaling as shown in Table 1 (c and $\mathrm{g}$ ).

\subsection{Reactive Siliceous Aggregates}

The occurrence of extensive map cracking in the bathrooms areas and on the surfaces of nearby slabs, and beams, where humid and hot temperatures exist, confirmed the presence of expansive alkali-silica reaction in some elements 
in the building as shown in Table 1 (d). This could be due to the use of highly reactive siliceous aggregates, and cements with high alkalies in some concrete mixes, ASTM C150 [22].

\section{Rehabilitation Techniques Suggested}

The selection of the most appropriate repair technique is a crucial step in the rehabilitation scheme of the structure. It depends on many factors including the amount of damage, location and shape of the defect in the structure, the availability of repair materials and experienced technician, construction cost, and time. The repair scheme of the precast concrete structure inspected started with the elements, which experienced excessive deflection, followed by the elements, which suffered extensive deterioration, and severe cracking. The members, which experienced slight damage, and fine to moderate cracks, were repaired at a later stage.

\subsection{Structural Repair of Deflected Members}

The slabs whose measured deflections exceeded the deflection limit specified in the ACI/SBC codes, were strengthened by installing I-section steel beams of size HE240A on the tension side at the middle of the span as shown in Figures 8 and 9. Moreover, the deflections of the cantilever slabs were reduced by installing I-section steel beams of size HE1600A on the tension side at equal distances as shown in the same figures.

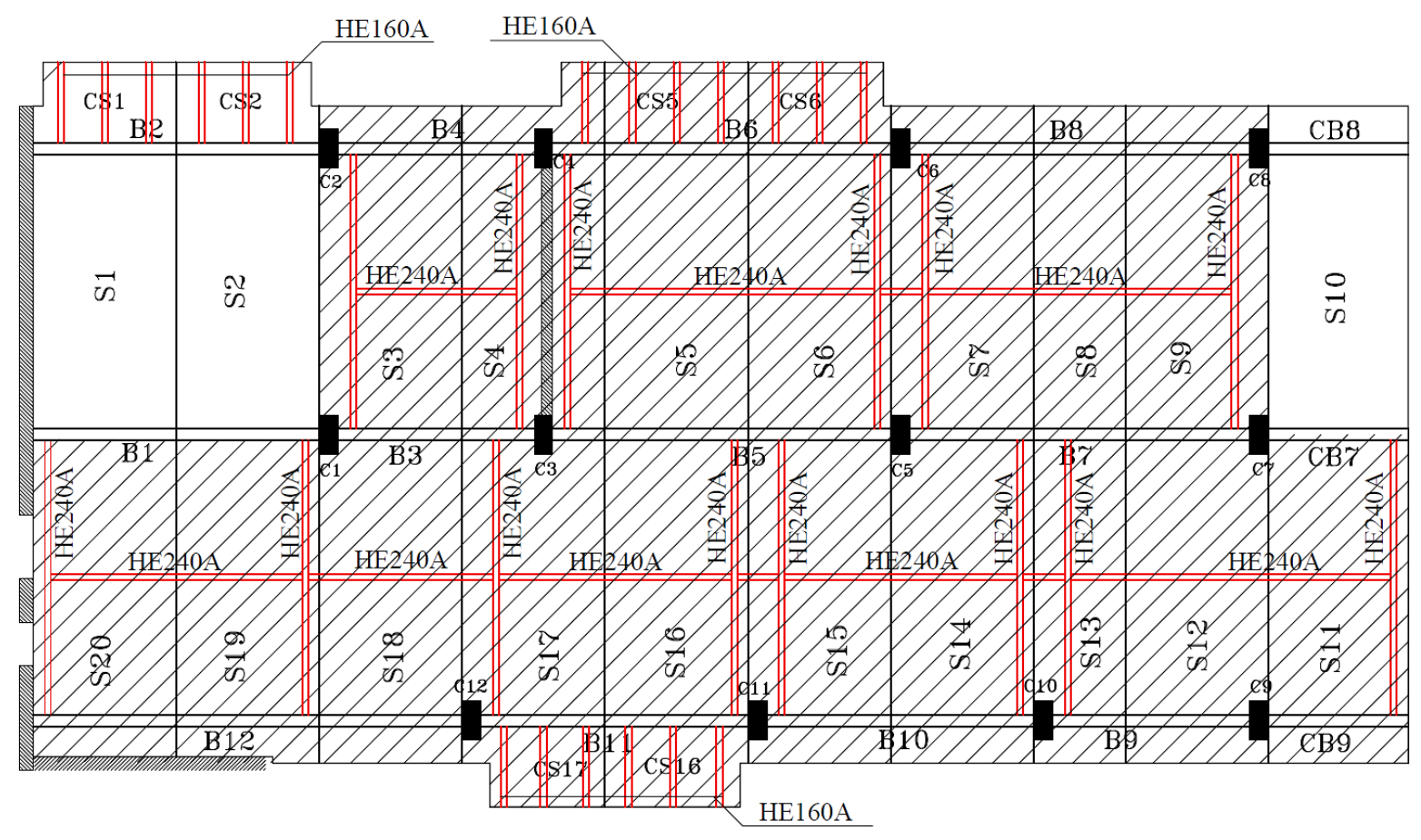

Figure 8. A layout of supported slabs for a single apartment

\subsection{Structural Repair of Columns, Beams and Slabs against Corrosion Damage}

The repair method proposed in this study to prevent the concrete damage induced by chloride corrosion and moisture in some structural elements consists of: removing the concrete cover including cracked and delaminated concrete to about $25 \mathrm{~mm}$ behind the bar using mechanical means; cleaning the corroded steel bar by sandblasting or wire brush; at areas where the corroded bars have lost more than $20 \%$ of their diameter, additional bars were used and spliced in to guarantee structural integrity; removing dust by air blowing and washing with clean water to achieve a saturated surface dry substrate; coating the exposed steel bars with a zinc rich product (such as Sika Zinc Rich® or similar material) to protect it against corrosion and to delay the attack of aggressive elements; cathodic protection of the corroded steel bars was conducted using either a mesh or ribbon anode system, covered by a cementituous overlay such as gunite, or a discrete anode system where anodes are individually placed on, or in the concrete surface [23-25]; applying a high strength cementitious repair mortar or concrete to restore the removed concrete cover [26]; in case the required thickness is less than $100 \mathrm{~mm}$, repair material such as SikaRep ${ }^{\circledR}$ or similar can be used; in case the required thickness is higher than $100 \mathrm{~mm}$, shotcrete must be used; and curing the applied repair mortar or concrete for a minimum of 7 days. Bonding agents should not be used where electrochemical treatment is required as it could create an insulating layer. Some of the beams and columns having corrosion, and severe cracks or a compressive strength less than $25 \mathrm{MPa}$, were strengthened further using carbon fiber reinforced polymer sheets (CFRP), or steel jackets as shown in the subsequent sections. 


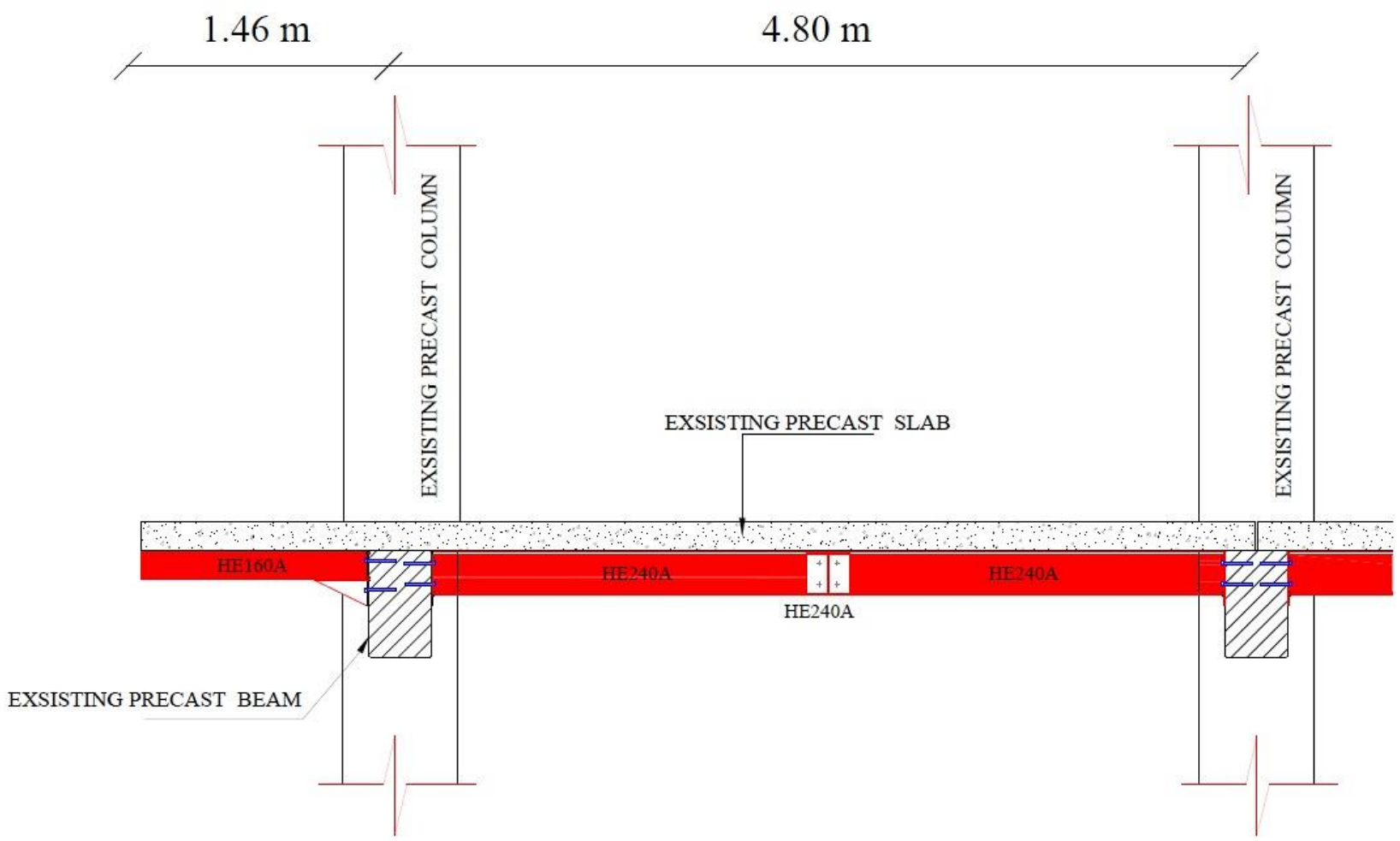

Figure 9. Details of supported slabs using wide flange steel beams of I section

\subsubsection{Strengthening of Columns using CFRP Sheets}

CFRP strengthening of some deteriorated columns was performed to enhance their strength and ductility, following the completion of the repair steps shown above, by installing 4 layers of carbon fiber wrap (sheets $/ \mathrm{type} 300 \mathrm{gr} / \mathrm{m}^{2}$ unidirectional) around the column sides for the complete length of columns, with (100 mm) overlapping of layers as shown in Figure 10.

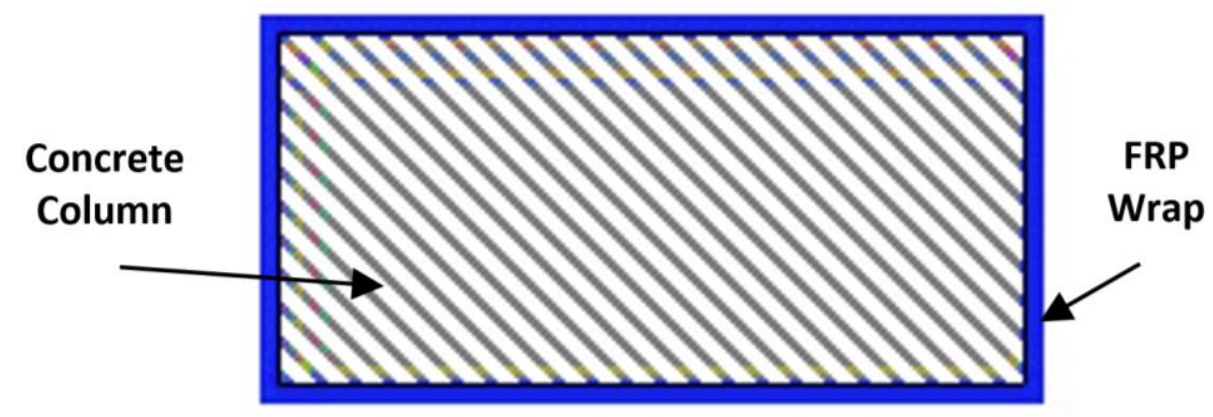

Figure 10. Sectional view of column strengthening using CFRP

\subsubsection{Strengthening of Columns using Steel Jackets}

Steel jacketing strengthening of some columns was also performed using high tensile strength steel sheets of 10 $\mathrm{mm}$ thickness to enhance their strength and ductility as follows: welding all sides of the plates strongly at the column corners; placing epoxy injection nipples in the steel sheets from different sides of the column as shown in Figures 11 and 12. Sealing all bottom sides of steel sheet with epoxy resin; epoxy injection through the nipples should start from bottom to top of the column to fill all air gaps between the concrete column, and the steel sheets of the jacket; drilling $20 \mathrm{~mm}$ tie rods through the center of the column at a spacing of $0.5 \mathrm{~m}$ and placing the tie rods in the holes and fastening using washer and nuts. 


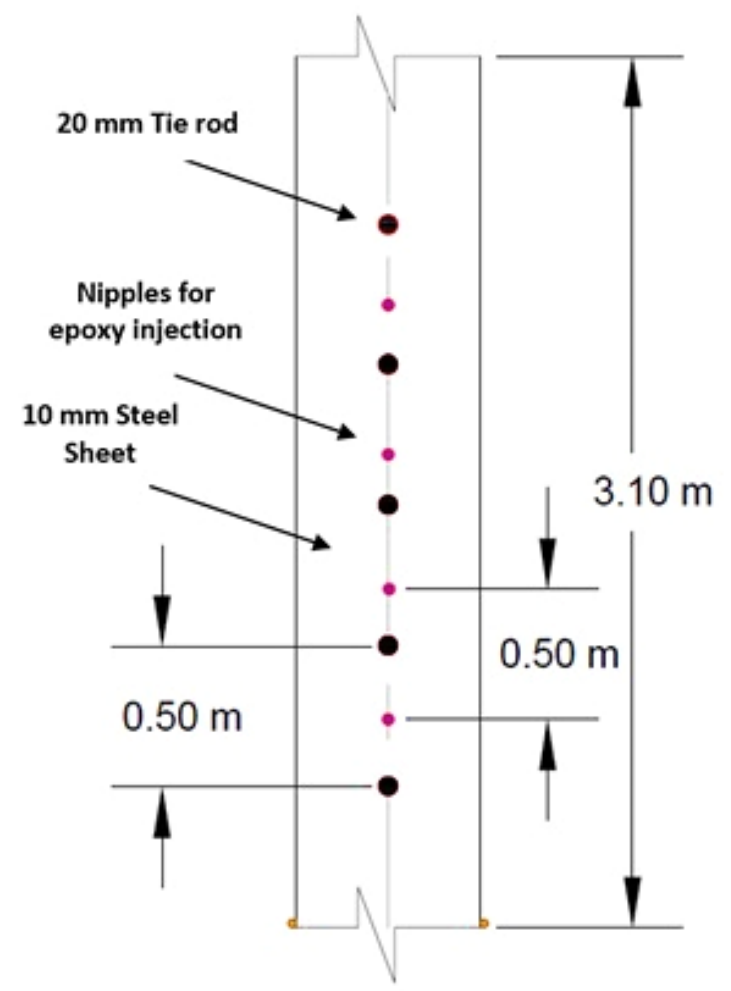

Figure 11. Elevation view of the column strengthened using steel jacketing

\subsubsection{Strengthening of Beams Using CFRP Sheets}

The strengthening of the damaged beams was performed using CFRP sheets to increase their moment capacity and ductility. It included: installing one carbon fiber laminate (strips $/ 100 \mathrm{~mm}$ wide and $1.4 \mathrm{~mm}$ thick) at the bottom of the full span of the beam as shown in Figure 13; installing 2 layers of U shape carbon fiber wrap (sheets/type $300 \mathrm{gr} / \mathrm{m}^{2}$ unidirectional) on the three sides of the beam, for one fourth of the beam span length beside the column with (100 $\mathrm{mm}$ ) overlapping between layers. Total number of the beams in the building was 335 beams; out of which 62 beams (19\%) requiring strengthening by CFRP sheets.

\subsection{Structural Repair of Slabs against ASR, and Salt Scaling Damage}

The repair method implemented in this study to counteract the moderate concrete damage caused by alkali silica reaction, ASR, and salt scaling included the following steps: the area of damaged concrete was bordered using a marker pen; breaking the concrete beyond the bordered area until reaching a sound concrete, using a jack hammer for saw-cutting the perimeter of the broken area to avoid feathered edges; damaged and easily removable concrete was chipped away; the dust was removed by air blowing and washed with clean water to achieve saturated surface dry substrata; bonding low viscosity material such as epoxy resin on the surface of old concrete to ensure full bond with the new concrete overlay; covering the broken concrete area with a suitable wooden forms; injecting a high strength cementitious grout at specific locations through holes in the forms using an injection pump [27]; the cementitious grout should be flowable, and contains silica fume and fly ash and had a water to cementitious materials ratio not exceeding 0.4 by weight of cement [28]; and curing the water tight overlay for a period of one week. For the structural members which suffered severe damage of more than $30 \%$ of their surface area, external strengthening of the defects injected with high strength cementitious grouts, using CFRP strips and or jackets would be a better choice for enhancing their flexural capacity and maximizing their service life. The high strength cementitious grout implemented provides a water-tight overlay on the damaged spot, and could be an ideal solution for improving the imperviousness of the concrete. 


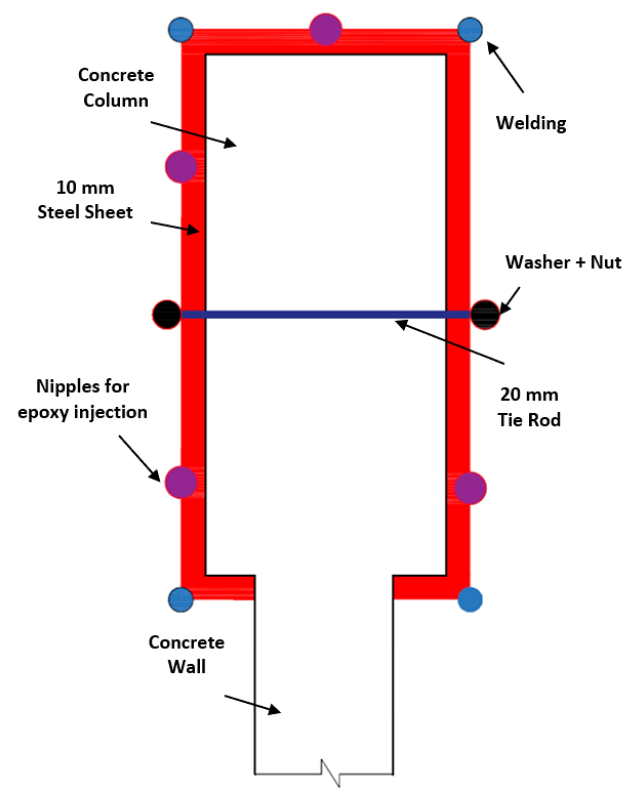

Figure 12. Sectional view of the column strengthening by steel jacketing

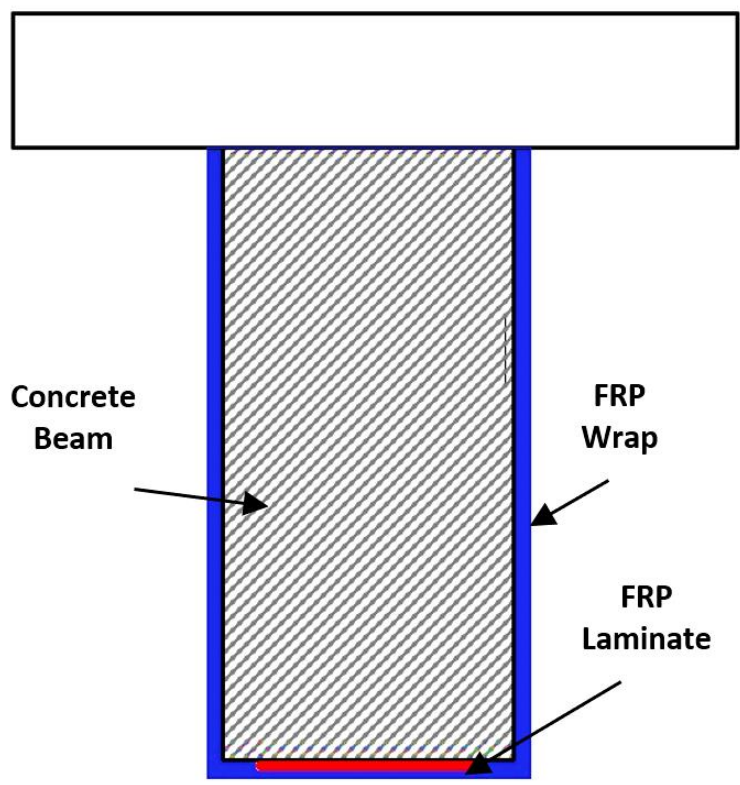

Figure 13. Sectional view of beam strengthening using CFRP

\subsection{Repair against Drying Shrinkage Cracks and Other Types of Structural Cracks}

For fine shrinkage cracks narrower than $1 \mathrm{~mm}$ in width, polymer sealant such as low viscosity epoxy resin is a better choice for filling the crack. Moreover, polymer injection could be used to ensure full penetration of the epoxy into the crack. For larger crack width, more than $1 \mathrm{~mm}$; make sure that the cracks are dormant and not growing with time. Crack injection using low viscosity epoxy resin was carried out as follows: using power driven wire brushes or grinder to remove surface laitance and any deposits along the line of the crack; using oil free compressed air to blow the dust off from the crack; chasing out along the line of the crack; cleaning the dust and apply the resin to seal the crack at the surface using scraper; fixing the injection nipples/packers; marking out positions of holes staggered on either side of the crack at $300 \mathrm{~mm}$ intervals, positioned so that they will intersect the line of the crack approximately half way in the concrete, when drilled at an angle of $45^{\circ}$; a percussion drill of $10 \mathrm{~mm}$ diameter was used to drill the holes marked on either side of crack by making sure that the drill passes the plane of the crack; removing the dust from the drilled holes; fixing injection packers made of steel, $10 \mathrm{~mm}$ dia., 50 to $60 \mathrm{~mm}$ long, in the drilled holes using the resin; and connecting the hose from the injection pump to the nipples, [28].

The epoxy resin used for injecting the cracks consist of two components (reactor and base). Its preparation process included: pouring the reactor on the base and mixing thoroughly for one minute; pouring the mixed material into the 
hopper/gun of the injection machine; depending on the width and depth of the crack a pressure of 50 bar is applied; start injecting the resin at one end of the crack untill it starts to flow from the next port; close the injected port and move to the next one, continue in a similar way, until completion, and allow the resin to cure, then remove the injection ports and level off the surface of the crack.

\subsection{Sustainability and Estimated Cost of the Repaired Structure}

The structural design of the repaired precast building was checked under the actual applied loads and a concrete strength of $20 \mathrm{MPa}$, using ETABS design software. All the elements of the repaired building were found to be safe according to the specifications of ACI318-14 and SBC304-18, [5, 17]. Moreover, some of the repair techniques implemented could extend the service life of the precast structure for a minimum of 6 years. The total estimated cost of repairs was found to be 3 million SR ( 0.8 million \$), which represent about $20 \%$ of the original cost of the building. This cost is expected to be compensated by renting all apartments of the building for three years, based on a current yearly rate of 35000 SR (9333 \$) for renting a single apartment in Riyadh.

\section{Conclusions}

This study evaluated the condition of a multi-storey aging precast concrete structure built in1980, and proposed appropriate repair techniques for maximizing its service life at a reasonable cost. Based on the analytical, visual and experimental investigations performed the following conclusions can be drawn:

- The analytical check of the safety of the structure using modern tools such as ETABS and SAFE softwares, revealed excessive deflections of some slabs as a result of design error.

- The visual inspection of the building indicated that no major maintenance was carried out since a long period of time. Defects identified included steel corrosion, alkali-aggregate reaction, water leakage, salt scaling, leaching, and cracking.

- The experimental test results obtained from several core samples collected from different locations in the structure showed low quality concrete containing less cement contents and high concentrations of chlorides. Further analysis of the field tests confirmed the occurrence of poor workmanship during the construction stage of the building.

- Based on the level of damage of the deteriorated members, the most appropriate and state of the art repair techniques and materials proposed include:

- Removal of the deteriorated concrete, and pouring bonding agent on the surface of the damage, followed by injecting a high strength cementitious grout.

- Supporting some slabs using I-section, wide flange steel beams to reduce the deflection.

- Using cathodic protection of corroded steel bars for preventing the chloride corrosion from spreading to the reinforcement of nearby members.

- Injecting high strength cementitious grouts (patch repairs) over the damaged areas, followed by sufficient curing and further strengthening using either carbon fiber reinforced polymer sheets or steel jackets.

- Strengthening the damaged beams and columns using (CFRP) sheets, and steel jackets for enhancing their strength and ductility.

- The repair and strengthening techniques implemented in this investigation are expected to extend the life span of the precast concrete building for a minimum of 6 years at a limited cost of its annual rent cost.

- Conducting further experimental tests on load-displacement response and microstructure of some concrete samples would reveal valuable information on the mechanical behavior and composition of the concrete used respectively. Moreover, enhancing the seismic resistance of the structure through the use of advanced strengthening techniques will definitely extend its life span further.

\section{Acknowledgements}

The authors would like to acknowledge the support provided by the Deanship of Scientific Research at King Saud University, through the Research Centre at the College of Engineering.

\section{Conflicts of Interest}

The authors declare no conflict of interest. 


\section{References}

[1] ACI Committee 546, "ACI546-R-04 Concrete Repair Guide", American Concrete Institute, Farmington Hills, Michigan, (2004).

[2] Shannag, M. Jamal, and Suzan A. Al-Ateek. "Flexural Behavior of Strengthened Concrete Beams with Corroding Reinforcement." Construction and Building Materials 20, no. 9 (November 2006): 834-840. doi:10.1016/j.conbuildmat.2005.01.059.

[3] Broomfield, J.P., J. Rodriguez, I.M. Ortega, and A.m. Garcia. "Corrosion Rate Measurement and Life Prediction for Reinforced Concrete Structures.” Structural Faults and Repair (1993): 155-164.

[4] SBC 304, "Concrete Structures", the Saudi Building Code, Riyadh, Saudi Arabia, (2018).

[5] El-Reedy, Mohamed Abdallah. "Repair of Reinforced Concrete Structures." Steel-Reinforced Concrete Structures (November 6, 2017): 153-180. doi:10.1201/b22237-8.

[6] Shannag, M. Jamal, Nabil M Al-Akhras, and Sami F. Mahdawi. "Flexure Strengthening of Lightweight Reinforced Concrete Beams Using Carbon Fibre-Reinforced Polymers.” Structure and Infrastructure Engineering 10, no. 5 (January 23, 2013): 604613. doi:10.1080/15732479.2012.757790.

[7] Nayak, A.N., A. Kumari, and R.B. Swain. "Strengthening of RC Beams Using Externally Bonded Fibre Reinforced Polymer Composites.” Structures 14 (June 2018): 137-152. doi:10.1016/j.istruc.2018.03.004.

[8] Siddika A, Mamun MA Al, Alyousef R, Amran YHM. "Strengthening of reinforced concrete beams by using fiber-reinforced polymer composites: A review.” Journal of Building Engineering (September 2019):100798. doi:10.1016/j.jobe.2019.100798.

[9] Naser, M.Z., R.A. Hawileh, and J.A. Abdalla. "Fiber-Reinforced Polymer Composites in Strengthening Reinforced Concrete Structures: A Critical Review.” Engineering Structures 198 (November 2019): 109542. doi:10.1016/j.engstruct.2019.109542.

[10] Rastegarian, Saeed, and Ashkan Sharifi. "An Investigation on the Correlation of Inter-Story Drift and Performance Objectives in Conventional RC Frames.” Emerging Science Journal 2, no. 3 (2018). doi:10.28991/esj-2018-01137.

[11] Balamuralikrishnan, R., and Saravanan J., "Finite Element Modelling of RC T - Beams Reinforced Internally with GFRP Reinforcements." Civil Engineering Journal 5, no. 3 (2019): 563. doi:10.28991/cej-2019-03091268.

[12] Venkatesh, Preethi, and Mallika Alapati. "Condition Assessment of Existing Concrete Building Using Non-Destructive Testing Methods for Effective Repair and Restoration-A Case Study.” Civil Engineering Journal 3, no. 10 (2017): 841. doi:10.28991/cej-030919.

[13] Vijayalakshmi, R., S. Ramanagopal, R. Sathia, and R. Arvindh Raj. "Case Study on the Repair and Rehablitation of G+3Residential Appartment Located Near Sea Shore, Tamil Nadu, India.” Indian Journal of Science and Technology 10, no. 26 (2017): 1-7. doi:10.17485/ijst/2017/v10i26/115874.

[14] Raza, Saim, Muhammad K. I. Khan, Scott J. Menegon, Hing-Ho Tsang, and John L. Wilson. "Strengthening and Repair of Reinforced Concrete Columns by Jacketing: State-of-the-Art Review.” Sustainability 11, no. 11 (2019): 3208. doi:10.3390/su11113208.

[15] Parks, Joel E., Dylan N. Brown, M. J. Ameli, and Chris P. Pantelides. "Seismic Repair of Severely Damaged Precast Reinforced Concrete Bridge Columns Connected with Grouted Splice Sleeves.” ACI Structural Journal 113, no. 3 (2016). doi:10.14359/51688756.

[16] Fofiu, Mihai, Andrei Bindean, and Valeriu Stoian. "Carbon Fiber Strips Retrofitting System for Precast Reinforced Concrete Wall Panel.” Key Engineering Materials 660 (2015): 208-212. doi:10.4028/www.scientific.net/kem.660.208.

[17] ACI 318-14, "Building Code Requirements for Structural Concrete", American Concrete Institute, Farmington Hills, Michigan, (2014).

[18] ASTM C805, "Standard Test Method for Rebound Number of Hardened Concrete", American Society for Testing and Materials, West Conshohocken, PA, (2018).

[19] ASTM C42, "Standard Test Method for Obtaining and Testing Drilled Cores and Sawed Beams of Concrete", American Society For Testing And Materials, West Conshohocken, PA, (2020).

[20] ASTM C 39, "Standard test method for compressive strength of cylindrical concrete specimens" American Society for Testing and Materials, West Conshohocken, PA, (2005).

[21] Neville, A.M., "Properties of concrete: Fourth Edition", (1997).

[22] ASTM C150/ C150M - 19a, "Standard Specification for Portland Cement", American Society For Testing And Materials, West Conshohocken, PA, (2019). 
[23] Takewaka, K., and Matsumoto, S. "Quality and Cover Thickness of Concrete Based on the Estimation of Chloride Penetration in Marine Environments.” American Concrete Institute (ACI), (1988): 381-400.

[24] Rahman, M. Kalimur, Walid A. Al-Kutti, Mohammed A. Shazali, and Mohammed H. Baluch. "Simulation of Chloride Migration in Compression-Induced Damage in Concrete." Journal of Materials in Civil Engineering 24, no. 7 (July 2012): 789-796. doi:10.1061/(asce)mt.1943-5533.0000458.

[25] Mangat, P.S., and M.C. Limbachiya. "Repair Material Properties for Effective Structural Application." Cement and Concrete Research 27, no. 4 (April 1997): 601-617. doi:10.1016/s0008-8846(97)00027-6.

[26] Shannag, M.Jamal. "High-Performance Cementitious Grouts for Structural Repair.” Cement and Concrete Research 32, no. 5 (May 2002): 803-808. doi:10.1016/s0008-8846(02)00710-x.

[27] Shannag, M.J., and S.M. Mourad. "Flowable High Strength Cementitious Matrices for Ferrocement Applications." Construction and Building Materials 36 (November 2012): 933-939. doi:10.1016/j.conbuildmat.2012.06.051.

[28] RILEM Committee, "Draft Recommendation for Repair Strategies for Concrete Structures Damaged by Reinforcement Corrosion." Materials and Structures 27, no. 7 (August 1994): 415-436. doi:10.1007/bf02473446. 